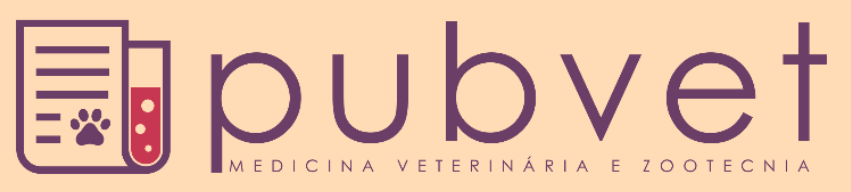

https://doi.org/10.31533/pubvet.v15n08a896.1-8

\title{
Produção de leite de vacas zebuínas manejadas em pastagens tropicais
}

\author{
Wallacy Augusto de Oliveira ${ }^{1} \bullet$, Maurício Scoton Igarasi ${ }^{2} \bullet$, Marco Túlio Gonçalves Peres ${ }^{3}$, \\ Jonathan de Oliveira Gonçalves $^{1 \bullet}$, Aline Martelo Pereira ${ }^{4} \bullet$, Lucas Vieira Silva ${ }^{5 *} \bullet$ (D) \\ ${ }^{I}$ Méd. Vet., Mestrando em Sanidade e Produção Animal nos trópicos, Universidade de Uberaba - Uniube - Uberaba - MG, Brasil. \\ ${ }^{2}$ Docente do curso de graduação em Medicina Veterinária e do Programa de Mestrado em Sanidade e Produção Animal nos Trópicos da-Uniube-MG, Brasil. \\ ${ }^{3}$ Méd. Vet., Universidade de Uberaba - Uniube - Uberaba - MG, Brasil. \\ ${ }^{4}$ Méd. Vet., M. Sc em Sanidade e Produção Animal nos trópicos - Universidade de Uberaba - Uniube - Uberaba - MG, Brasil. \\ ${ }^{5}$ Eng. Agr., Mestrando em Zootecnia - Universidade Federal de Viçosa, Viçosa - MG, Brasil. \\ *Autor para correspondência, E-mail: lucastc96@gmail.com
}

Resumo. A produção de leite brasileira é caracterizada pela exploração de pastagens tropicais, com a utilização de animais zebuínos, puros ou cruzados o com raças europeias leiteiras. A composição do leite é fator importante na eficiência econômica de toda a cadeia de produção. O objetivo do trabalho foi avaliar a produção e composição de leite de vacas de diferentes tipos raciais em pastagens tropicais. O experimento foi realizado na Fazenda Estância Orestes Prata Tibério Junior da (ABCZ), sendo utilizado a área experimental de 20 ha formada por 13 piquetes em sistema de pastejo rotativo, com pastagem de Brachiaria Brizantha cv Paiaguas. Os animais foram manejados com 1 dia de ocupação em cada piquete, com oferta de $10 \%$ do peso vivo animal em forragem (MS). O período experimental foi de 18 dias, sendo 13 dias de adaptação e 5 dias de avaliações. O suplemento proteico-energético ( $28 \%$ de PB) foi fornecido individualmente na razão de $1 \mathrm{~kg}$ de para cada $3 \mathrm{~kg}$ de leite produzido, sendo parcelado duas vezes ao dia, sempre após a ordenha. Foram avaliadas 14 vacas leiteiras, sendo oito da raça Gir, duas da raça Sindi e três animais Guzolando. A ordenha foi realizada duas vezes por dia, às 5:00 e às 16:00 horas. A pesagem do leite foi feita diariamente. As análises de gordura e de sólidos não gordurosos (SNG), contemplando proteína, carboidratos, minerais e vitaminas, foram realizadas pelo processo de infravermelho com analisador Bentley 2000 (Bentley Instruments ${ }^{\circledR}$ ). Foi utilizado o delineamento inteiramente casualizado, tendo 3 tratamentos (raças Gir, Sindi e Guzolando) e cada animal correspondeu a uma unidade experimental. A comparação de médias foi realizada pelo teste Tukey com nível de significância de $5 \%$. A produção de leite foi superior $(\mathrm{P}=0,0007)$ para a raça Guzolanda $\left(20,02 \mathrm{~kg}\right.$.dia $\left.{ }^{-1}\right)$, sendo

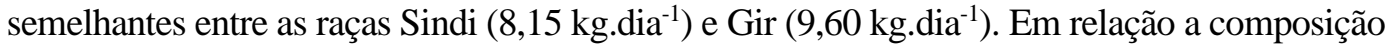
do leite, tanto a produção de gordura quanto a produção de sólidos não gordurosos, houve efeito de raça $(\mathrm{P}=0,0017$ e $\mathrm{P}=0,0006$, respectivamente). A raça Guzolanda foi superior em ambas características de composição do leite, apresentando produção de gordura de $0,72 \mathrm{~kg}$.dia ${ }^{-1}$ e de

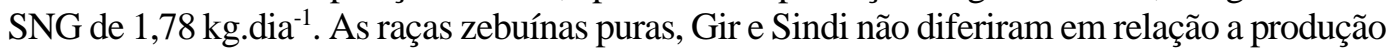
de gordura (0,32 e 0,26 kg.dia ${ }^{-1}$, respectivamente) e SNG $\left(0,87\right.$ e $\left.0,77 \mathrm{~kg}_{\text {dia }}{ }^{-1}\right)$. Dessa forma, foi possível concluir que o cruzamento promoveu ganhos na produção e na composição do leite em sistemas de pastagens tropicais.

Palavras chave: Cruzamento Holandês, Gir, Sindi, sólidos totais

\section{Milk yield of zebu cows managed on tropical pastures}

Abstract. Brazilian milk production is characterized by the exploitation of tropical pastures, using
zebu animals, purebred or crossed with European dairy breeds. Milk's composition is an important
factor in the economic efficiency of the entire production chain. The objective of this study was
to evaluate the milk production and composition of cows of different racial types in tropical
pastures. The experiment was carried out at Fazenda Estância Orestes Prata Tiberio Junior of 
Brazilian Zebu Breeders Association (ABCZ) using the 20 ha experimental area formed by 13 paddocks in a rotational grazing system, with Brachiaria Brizantha cv Paiaguas pasture. The animals were handled with 1 day of occupation in each paddock, offering $10 \%$ of the animal live weight in forage (DM). The experimental period was 18 days, with 13 days of adaptation and 5 days of evaluations. The protein-energetic supplement $(28 \% \mathrm{CP})$ was supplied individually at the rate of $1 \mathrm{~kg}$ for each $3 \mathrm{~kg}$ of milk produced, being parceled twice a day, always after milking. 14 dairy cows were evaluated, 8 of the Gyr breed, 2 of the Sindi breed and 3 Guzolando animals. Milking was performed twice a day, at 5:00 am and 4:00 pm. Weighing the milk was done daily. The analysis of fat and non-fat solids (SNG), including protein, carbohydrates, minerals and vitamins, were carried out by the infrared process with a Bentley 2000 analyzer (Bentley Instruments $($ )). A completely randomized design was used, with 3 treatments (Gyr, Sindi and Guzolando breeds) and each animal corresponded to an experimental unit. The comparison of means was performed by the Tukey test with a 5\% significance level. Milk production was higher $(\mathrm{P}=0.0007)$ for the Guzolanda breed $\left(20.02 \mathrm{~kg}^{-} \mathrm{day}^{-1}\right)$, being similar between the Sindi $(8.15$ kg.day ${ }^{-1}$ ) and Gir (9.60) kg.day ${ }^{-1}$ ). Regarding the composition of milk, both the production of fat and the production of non-fat solids, there was an effect of race $(\mathrm{P}=0.0017$ and $\mathrm{P}=0.0006$, respectively). The Guzolanda breed was superior in both characteristics of milk composition, presenting fat production of $0.72 \mathrm{~kg}$.day ${ }^{-1}$ and SNG of $1.78 \mathrm{~kg}^{\text {.day }}{ }^{-1}$. The pure zebu breeds, Gyr and Sindi did not differ in relation to fat production $\left(0.32\right.$ and $0.26 \mathrm{~kg}^{-d a y^{-1}}$, respectively) and SNG $\left(0.87\right.$ and $\left.0.77 \mathrm{~kg} \cdot \mathrm{day}^{-1}\right)$. Thus, it was possible to conclude that the crossing promoted gains in milk production and composition in tropical pasture systems.

Key words: Crossbreeding Holstein cattle, Gyr, Sindi, total solids

\section{Producción de leche de vacas cebú manejadas en pastos tropicales}

Resumen. La producción de leche brasileña se caracteriza por la explotación de pastos tropicales, con el uso de animales cebú, de raza pura o cruzados con razas lecheras europeas. La composición de la leche es un factor importante en la eficiencia económica de toda la cadena de producción. El objetivo del trabajo fue evaluar la producción y composición de leche de vacas de diferentes tipos raciales en pastos tropicales. El experimento se lleva a cabo en la Fazenda Estância Orestes Prata Tibério Junior da (ABCZ), utilizando el área experimental de 20 ha formada por 13 potreros en un sistema de pastoreo rotacional, con pasto Brachiaria Brizantha cv Paiaguas. Los animales se manejaron con 1 día de ocupación en cada potrero, ofreciendo el $10 \%$ del peso vivo del animal en forraje (MS). El período experimental fue de 18 días, con 13 días de adaptación y 5 días de evaluaciones. El suplemento proteico-energético $(28 \%$ PC) se suministró individualmente a razón de $1 \mathrm{~kg}$ por cada $3 \mathrm{~kg}$ de leche producida, siendo parcelado dos veces al día, siempre después del ordeño. Se evaluaron 14 vacas lecheras, 8 de la raza Gir, 2 de la raza Sindi y 3 animales Guzolando. El ordeño se realizó dos veces al día, a las 5:00 am y a las 4:00 pm. El pesaje de la leche se llevó a cabo a diario. Los análisis de sólidos grasos y no grasos (SNG), incluidas proteínas, carbohidratos, minerales y vitaminas, se efectuaron mediante el proceso de infrarrojos con un analizador Bentley 2000 (Bentley Instruments ${ }^{\circledR}$ ). Se utilizó un diseño completamente al azar, con 3 tratamientos (razas Gir, Sindi y Guzolando) y cada animal correspondió a una unidad experimental. La comparación de medias se realizó mediante la prueba de Tukey con un nivel de significancia del $5 \%$. La producción de leche fue mayor $(\mathrm{P}=0.0007)$ para la raza Guzolanda (20.02 kg.día $\left.{ }^{-1}\right)$, siendo similar entre los Sindhi $\left(8.15 \mathrm{~kg}_{\text {.día }}{ }^{-1}\right)$ y Gir (9.60) kg.día $\left.{ }^{-1}\right)$. En cuanto a la composición de la leche, tanto la producción de grasa como la producción de sólidos no grasos, hubo efecto de raza $(\mathrm{P}=0.0017$ y $\mathrm{P}=0.0006$, respectivamente). La raza Guzolanda fue superior en ambas características de composición de la leche, con producción de grasa de $0,72 \mathrm{~kg}$.día ${ }^{-1} \mathrm{y}$ SNG de 1,78 kg.día ${ }^{-1}$. Las razas pura cebú, Gir y Sindi no difirieron en relación a la producción de grasa $\left(0.32\right.$ y $0.26 \mathrm{~kg}$.día ${ }^{-1}$, respectivamente) y SNG $\left(0.87\right.$ y $0.77 \mathrm{~kg}$.día $\left.{ }^{-1}\right)$. Así, fue posible concluir que el cruce promovió ganancias en la producción y composición de la leche en los sistemas de pastos tropicales.

Palabras clave: Cruce ganado Holandés, Gir, Sindi, sólidos totales 


\section{Introdução}

A bovinocultura brasileira tem por característica a utilização de pastagens tropicais, visto as extensas áreas com forrageiras. Essas características favoráveis ao desempenho e à produtividade do animal no país ainda não apresentam eficiência satisfatória, tanto do ponto de vista biológico quanto do econômico (Fukumoto et al., 2010; Manzano et al., 2007). Para produzir leite eficientemente, necessita-se intensificar a atividade e otimizar a produção de forrageiras, realizando sua escolha de forma criteriosa, atingindo maior produtividade de matéria seca e conteúdo de nutrientes, com equilíbrio estacional e aceitabilidade pelos animais (Figueiredo et al., 2018).

Com o aumento populacional tem crescido a demanda pela produção de leite, o que como consequência, exige dos produtores maior produtividade, aprimorando suas técnicas e aplicando cada vez mais tecnologia, como por exemplo, o uso de dietas balanceadas. Estas mudanças criam desafios para o produtor, pois muitas vezes interferem diretamente no custo de produção e alterando a margem de lucro (Figueiredo et al., 2018).

Alguns autores (Gomide, 1998; Hack et al., 2007; Silva et al., 2008) defendem a produção de leite a pasto como um sistema de baixo custo, especialmente nos países em desenvolvimento. (Figueiredo et al., 2018). Otimizar o uso eficiente de nutrientes pelo animal, pode gerar retornos econômicos e melhorar a qualidade do leite (Oliveira Filho et al., 2018). Obter informações sobre a eficiência alimentar e parâmetros produtivos de fêmeas zebuínas, taurinas e mestiças, criadas em condições tropicais, tornase necessário para estabelecer o valor nutritivo das dietas e requisitos nutricionais, melhorando a eficiência dos sistemas de produção de leite (Oliveira Filho et al., 2018).

No Brasil, algumas raças e cruzamentos são mais adaptadas ao clima tropical, tornando possível produzir leite ao menor custo. Contudo, são escassos os dados para a formulação de dietas para animais leiteiros zebuínos e cruzados (Oliveira Filho et al., 2018).

O objetivo desse trabalho foi avaliar a produção e composição de leite de vacas de diferentes raças e cruzamentos em pastagens tropicais.

\section{Material e métodos}

O trabalho foi realizado na Fazenda Estância Orestes Prata Tibério Júnior na cidade de Uberaba, MG. A área experimental (20 ha) é formada por 13 piquetes, $(0,57 \mathrm{ha})$ em sistema de pastejo rotativo, com pastagem de Brachiaria brizantha cv Paiaguas. Os animais foram manejados com um dia de ocupação em cada piquete, com oferta de $10 \%$ do peso vivo em forragem (na base matéria-seca). O período experimental foi do dia 5 a 23 de abril de 2017, sendo 12 dias de adaptação e seis dias de avaliações.

Foram utilizadas 14 vacas leiteiras adultas (três a seis lactações) durante o terço médio da lactação (DEL de 100 a 200 dias), de diferentes raças e cruzamentos, sendo oito animais Gir, três animais Sindi e três animais Guzolando.

O suplemento foi fornecido duas vezes ao dia, sempre após a ordenha, em cochos com proteção individual e contenção, para controle de consumo e medição de sobras. Foi fornecido $1 \mathrm{~kg}$ de suplemento proteico-energético (Tabela 1) para cada três kg de leite produzido.

Tabela 1. Composição nutricional do suplemento energético-proteico fornecido para as vacas em experimento.

\begin{tabular}{lc}
\hline Características & Teores \\
\hline Teor de matéria-seca (\%) & 88 \\
Fibra detergente ácido (FDA, \% MS) & 8 \\
Fibra detergente neutro (FDN, \% MS) & 11 \\
Proteína bruta (PB, \% MS) & 28 \\
Extrato etéreo (EE, \% MS) & 2,5 \\
Fósforo (g/kg) & 5 \\
Cálcio (g/kg) & 10 \\
Vitamina A (UI) & 10000 \\
Vitamina D3 (UI) & 2000 \\
Vitamina E (UI) & 50 \\
Monensina sódica (mg/kg) & 40 \\
\hline
\end{tabular}


Para quantificação da massa de forragem foram realizadas dez amostragens em locais que representavam a condição média dos piquetes avaliados. Foi utilizada uma armação metálica de $0,50 \mathrm{x}$ $0,50 \mathrm{~m}(0,25 \mathrm{~m} 2)$ e a forragem foi colhida com auxílio de tesouras de jardinagem. As amostras da forragem foram secas em estufa de ar forçado a temperatura a $650^{\circ} \mathrm{C}$ por 72 horas e moídas em peneiras de $1 \mathrm{~mm}$. Realizaram-se as análises de matéria seca (MS\%), proteína bruta (PB, \%MS), fibra detergente neutro (FDN, \%MS), fibra detergente ácido (FDA, \%MS) e digestibilidade "in vitro" (DIVMS, \%MS), segundo Silva \& Queiroz (2002) (Tabela 2).

Tabela 2. Analise bromatológica da forragem durante o período experimental.

\begin{tabular}{lccccc}
\hline Piquetes & \% MS & FDN & FDA & PB & DIVMS \\
\hline 1 & 20,17 & 66,06 & 38,13 & 6,07 & 58,34 \\
2 & 22,73 & 64,71 & 37,37 & 5,72 & 56,39 \\
3 & 21,89 & 59,33 & 31,79 & 8,38 & 60,98 \\
4 & 19,50 & 67,14 & 38,34 & 3,96 & 55,21 \\
5 & 20,52 & 64,95 & 35,72 & 4,73 & 58,83 \\
6 & 23,99 & 67,13 & 38,63 & 4,90 & 56,39 \\
\hline Média & 21,47 & 64,89 & 36,66 & 5,63 & 57,69 \\
Desvio padrão & 1,71 & 2,91 & 2,61 & 1,54 & 2,10 \\
\hline
\end{tabular}

A mensuração do consumo de forragem foi realizada com o marcador externo lignina purificada e enriquecida (LIPE ${ }^{\circledR}$, hidroxifenilpropano modificado e enriquecido) (Ferreira et al., 2009). Os animais receberam o indicador através de capsulas e introduzidas no rúmen. O período de uso do indicador foi de três dias, sendo primeiro e segundo dia para obtenção no equilíbrio do consumo e excreção, sendo que a amostragem foi realizada no terceiro, quarto e quinto dia sequentes (Valadares Filho et al., 2006). A amostragem foi realizada uma vez ao dia, em horário fixo com coleta de fezes retal. As amostras fecais foram secadas em estufa de ar forçado durante 72 horas em temperatura de $650^{\circ} \mathrm{C}$. As amostras foram analisadas no Laboratório de Nutrição da Escola de Veterinária da Universidade Federal de Minas Gerais (EV/UFMG), em espectrofotômetro com detector de luz infravermelho (FTIV), segundo método de Sarkanen \& Ludwig (1971).

A ordenha foi realizada durante o período experimental, sendo efetuada duas vezes por dia, às 5:00 e às 17:00 horas. A pesagem do leite foi realizada diariamente. Realizou-se a amostragem do leite de cada animal em cada ordenha (manhã e tarde), formando uma amostra única por animal. As amostras para composição do leite foram coletadas em um tubo de $100 \mathrm{ml}$ contendo 2-bromo-2-nitropropano-13-diol, homogeneizadas e refrigeradas abaixo de 100C. As análises de gordura, proteína, lactose e sólidos totais foram realizadas pelo processo de infravermelho com analisador Bentley 2000 (Bentley Instruments $^{\circledR}$ ).

A produção de leite foi corrigida para sólidos totais (LCST) conforme a fórmula:

LCST $=\left(12,3^{*} \mathrm{~g}\right.$ de gordura $)+\left(6,56^{*} \mathrm{~g}\right.$ de sólidos não-gordurosos $)-(0,0752 * \mathrm{~kg}$ de leite $)$.

A eficiência alimentar foi calculada através da média de produção de leite corrigida para sólidos totais em relação à média de consumo total de matéria seca em kg.

O experimento foi constituído por 3 tratamentos, referentes aos grupos genéticos (Gir, Sindi e Guzolando). O delineamento foi inteiramente casualizado. A unidade experimental foi cada vaca leiteira $(\mathrm{n}=14)$. Os dados foram analisados utilizando-se o PROC MIXED do pacote estatístico SAS ${ }^{\circledR}$ (Statistical Analysis System), versão 9.2 para Windows ${ }^{\circledR}$. Todos os conjuntos de dados foram testados quanto à normalidade da distribuição dos erros e homogeneidade de variâncias. A comparação entre as médias dos tratamentos foi realizada pelo teste Tukey ao nível de significância de 5\%.

\section{Resultados e discussão}

Zanin et al. (2017) afirmam que a intensificação da produção de leite à base de pastagens requer a escolha da espécie forrageira de forma criteriosa, visando à maior produtividade de matéria seca (MS) e conteúdo de nutrientes, com equilíbrio estacional e aceitabilidade pelos animais, porém, a ingestão de alimentos forrageiros via pastejo, não permite determinar o consumo de MS e nutrientes de forma precisa e exata, pela influência de inconstância de composição em teores nutricionais. No presente 
trabalho, pôde-se observar o consumo de matéria seca variando de $8,82 \mathrm{~kg} /$ dia da raça Guzolando, 9,85 $\mathrm{kg} / \mathrm{dia}$ para a raça Gir e 10,24 kg/dia para a raça Sindi. Lima et al. (2001) encontraram valores de consumo de matéria seca de 9,55 kg/dia e 9,12 kg/dia, para animais zebuínos (Tabela 3). Carvalho et al. (2019), em sua pesquisa, relataram consumo médio de matéria seca de $9.71 \mathrm{~kg} / \mathrm{dia}$ para de animais F1 (Taurino vs. Zebuíno), enquanto Carvalho et al. (2018) encontraram valores de $14.8 \mathrm{~kg} \mathrm{~kg} / \mathrm{dia}$ para animais F1 (cruzamento de Holandês vs. Gir) e $9.9 \mathrm{~kg} \mathrm{DM} /$ dia para animais Gir, para vacas alimentados com silagem de milho e concentrado.

Santos et al. (2014) inferiram que animais de grupos genéticos próximos apresentam pouca oscilação no consumo de matéria seca em pastejo, descrevendo em suas pesquisas com animais mestiços taurino e zebuíno (Holandês x Gir; Holandês vs. Guzerá; e Holandês vs. Nelore), que o consumo de MS em pastejo, para esses animais, em média é de $13.34 \mathrm{~kg}$, apesar de esboçarem variações nos níveis de produção de leite. $\mathrm{O}$ consumo de MS, encontrado pelos mesmos autores para vacas mestiças sem consumo de concentrado foi de $11,01 \mathrm{~kg} / \mathrm{dia}$. No presente estudo o consumo de MS de vacas mestiças, quando somando os valores de forragem mais concentrado, obteve-se para a raça guzolando 14,82 $\mathrm{kg} / \mathrm{MS} / \mathrm{dia}$, sendo 8,82 kg/MS de forragem e 6,01 kg/MS de concentrado. Lima et al. (2001) relataram $10,85 \mathrm{~kg} / \mathrm{MS} /$ dia para vacas mestiças, sendo $8,26 \mathrm{~kg} / \mathrm{MS}$ de forragem e $2,59 \mathrm{~kg} / \mathrm{MS}$ de concentrado, enquanto Condren et al. (2019) relatam consumo de $14.5 \mathrm{~kg} /$ dia de matéria seca (sendo destes $11,5 \mathrm{~kg}$ de volumoso ingerido via pastejo e $3 \mathrm{Kg}$ de concentrado), para vacas leiteiras mestiças de alta produção.

Valores superiores no consumo de concentrado foram registrados nesta pesquisa, sendo justificados pelo critério de fornecimento do mesmo, baseado em um $\mathrm{kg}$ de concentrado para cada três $\mathrm{kg}$ de leite produzido por dia. Cardoso et al. (2017) registraram valores de CMS/dia de vacas mestiças (Holandês vs. Gir) em aproximadamente $12,76 \mathrm{~kg} /$ dia. Araújo et al. (2018), trabalhando com pastejo sob lotação contínua em pastagem de Brachiaria brizantha e capim elefante anão (Pennisetum purpureum Schum cv. Mott) e suplementação individual de acordo com a produção de leite, utilizaram a proporção de $1 \mathrm{~kg}$ de concentrado para cada $3 \mathrm{~kg}$ de leite produzido, para o desenvolvimento da pesquisa, para animais puramente zebuínos (Gir vs. Guzerá). De acordo com Condren et al. (2019), trabalhando com alimentação a base de pastejo e concentrados, definiram que, desde que a formulação esteja devidamente balanceada, o fornecimento de maior quantidade de ração (comparação entre fornecimento de 3 e 6 $\mathrm{kg} / \mathrm{dia} / \mathrm{animal}$ ), até um certo limite fisiológico, estimulara uma maior produção de leite e consequente aumento no consumo MS.

O NRC (1989) recomenda para vacas em lactação com produção de $15 \mathrm{~kg}$ de leite com $4 \%$ de gordura, um consumo de $2,8 \%$ do peso corporal, correspondente a $14 \mathrm{~kg}$ de matéria seca para vacas com peso vivo médio de $500 \mathrm{~kg}$ - valores para suprir as exigências de mantença e produção. No presente estudo o consumo de MS das vacas utilizadas no experimento, foi baseado no que é preconizado pelo NRC. Com tudo, segundo Johansen et al. (2017) e Ramírez-Rivera et al. (2019), as relação de consumo é dependentes do fator MS da forrageira, que sofre influência da quantidade e qualidade das pastagens (que podem sofrer interferência direta da estação do ano), fatores genéticos e padrão racial, a área de pasto por animal, o número de partos e o tempo de parto/período de gestação.

Tabela 3. Consumo e produção de leite das vacas leiteiras de diferentes raças em pastagens tropicais.

\begin{tabular}{|c|c|c|c|c|c|}
\hline \multirow{2}{*}{ Características } & \multicolumn{3}{|c|}{ Grupos genéticos } & \multirow{2}{*}{ Desvio padrão } & \multirow{2}{*}{$P$} \\
\hline & Gir & Sindi & Guzolando & & \\
\hline Consumo de matéria seca forragem, $\mathrm{kg}$ & $9,85 \mathrm{a}$ & $10,24 \mathrm{a}$ & $8,82 b$ & 0,31 & 0,0006 \\
\hline Consumo de matéria seca concentrado, $\mathrm{kg}$ & $2,88 \mathrm{~b}$ & $2,45 b$ & $6,01 \mathrm{a}$ & 0,27 & 0,0001 \\
\hline Consumo de matéria seca total, $\mathrm{Kg}$ & $12,72 b$ & $12,68 b$ & $14,82 \mathrm{a}$ & 0,69 & 0,0026 \\
\hline Eficiência alimentar, $\mathrm{kg} / \mathrm{kg}$ & $0,70 \mathrm{~b}$ & $0,60 b$ & $1,26 \mathrm{a}$ & 0,05 & 0,0007 \\
\hline Produção de leite corrigido para sólidos totais, $\mathrm{kg}$ & $8,92 b$ & $7,61 b$ & $18,94 \mathrm{a}$ & 2,80 & 0,0007 \\
\hline Produção de leite, $\mathrm{kg}$ & $9,60 \mathrm{~b}$ & $8,15 b$ & $20,12 \mathrm{a}$ & 0,58 & 0,0007 \\
\hline Produção de sólidos não gordurosos, $\mathrm{kg}$ & $0,87 b$ & $0,77 b$ & $1,78 \mathrm{a}$ & 0,24 & 0,0006 \\
\hline Produção de gordura, kg & $0,32 b$ & $0,26 b$ & $0,72 \mathrm{a}$ & 0,04 & 0,0017 \\
\hline
\end{tabular}

P: efeito estatístico. Letras diferentes na linha mostram diferença estatísticas $(\mathrm{P}<0,05)$ entre os tratamentos. 
A produção de leite foi superior $(P=0,0007)$ para a raça Guzolando $\left(20,02 \mathrm{~kg}^{-\mathrm{dia}^{-1}}\right)$, sendo semelhantes entre as raças Sindi $\left(8,15 \mathrm{~kg} \cdot \mathrm{dia}^{-1}\right)$ e Gir $\left(9,60 \mathrm{~kg} \cdot \mathrm{dia}^{-1}\right)$. Cardoso et al. (2017) relataram produção de 10,33 kg/leite/dia para vacas mestiças (Holandês vs. Zebu), mantidas em sistema de pastejo utilizando braquiária e suplementadas com quatro kg de concentrado. Fukumoto et al. (2010) demonstraram produção de 9,1 kg/leite/dia de vacas mestiças (Holandês vs. Zebu) em sistema de pastejo rotacionado de capim Tanzânia. Araújo et al. (2018), relataram produções equivalente, em análise estatística com 5\% de significância no Teste Tukey, para animais das raças Gir vs. Guzerá, sendo suas produções de leite médias de 11.30 e $11.25 \mathrm{~kg} / \mathrm{dia}$, respectivamente, sendo que os animais foram expostos a pastejo contínuo (Brachiaria brizantha e capim elefante anão Pennisetum purpureum Schum cv. Mott) e suplementação, nas proporções de $1 \mathrm{~kg}$ de concentrado para cada $3 \mathrm{~kg}$ de leite produzido.

Deresz (2001) mostrou nos resultados de seu trabalho as produções médias de leite de 12 a 14 $\mathrm{kg} / \mathrm{vaca} /$ dia em pastagem de capim-elefante, sem suplementação com concentrado, quando manejado em lotação rotacionada durante a época das chuvas, valores esses superiores aos encontrados nas raças Sindi e Gir e inferiores à produção registrada para as vacas Guzolando. O mesmo autor estudando o efeito da suplementação da pastagem de capim-elefante com concentrado, sobre a produção de leite e a variação no peso vivo de vacas mestiças, verificou um pequeno aumento na produção média de leite, de 11,4 para 12,6 kg/vaca/dia, para os animais sem suplementação e com suplementação de $2 \mathrm{~kg} / \mathrm{vaca} / \mathrm{dia}$ de concentrado, respectivamente, na época das águas. Silva et al. (2017), em sua pesquisa com animais mestiços (Holandês vs. Zebu), alimentados em sistema de piquete rotacionado, com pastagem de Tanzania (Panicum maximum, Jacq. Cv. Tanzania), e submetidos a suplementação apenas com mistura mineral ad libitum e suplementação proteica energético (2 $\mathrm{kg} /$ dia), definiram que uso exclusivo de forragem não permite a máxima expressão de produção de leiteira para vacas mestiças. Além disso, definiu que o teor médio de de pastagens tropicais, embasado na MS, apesar de sofrer grande interferência da estação do ano, influencia diretamente no nível de produção de leite. O mesmo autor, destacou que o uso da suplementação promoveu aumentos médios de 19,51\% para a produção de leite, em comparação a animais que receberam apenas mistura mineral.

Em relação a composição do leite, tanto a produção de gordura quanto a produção de sólidos não gordurosos, houve efeito de raça $(\mathrm{P}=0,0017$ e $\mathrm{P}=0,0006$, respectivamente). A raça Guzolando foi superior em ambas características de composição do leite, apresentando produção de gordura de 0,72 kg.dia ${ }^{-1}$ e de SNG de $1,78 \mathrm{~kg}_{\text {.dia }}{ }^{-1}$. As raças zebuínas puras, Gir e Sindi não diferiram em relação a produção de gordura $\left(0,32\right.$ e $0,26 \mathrm{~kg}_{\text {.dia }}{ }^{-1}$, respectivamente $)$ e $\mathrm{SNG}\left(0,87\right.$ e $\left.0,77 \mathrm{~kg} \cdot \mathrm{dia}^{-1}\right)$. De acordo com dados obtidos por Fukumoto et al. (2010), vacas mestiças produziram teor de sólidos não gordurosos (SNG) de média 8,5\%, enquanto na presente pesquisa pôde-se encontrar valores de $9,1 \%$ na raça Gir, 9,5\% na raça Sindi e 8,9\% nas vacas Guzolando. Araújo et al. (2018), observaram diferença na composição do leite de vacas Gir e Guzerá. Este autor relata uma composição média de 4,5\% de gordura, $3,3 \%$ de proteína e $12,2 \%$ de sólidos totais para a raça Guzerá; e 4,1\% de gordura, 3,2\% de proteína e 12,0\% de sólidos totais para Gir. Mayilathal et al. (2019) coletaram dados de animais da raça Sindi em diferentes estações do ano, definindo valores médios gordura, proteína e sólidos totais de, 3,89 $\%, 3,30 \%$ e $11,61 \%$, respectivamente.

A maior produção de leite, gordura e SNG pra a raça Guzolando é devido ao efeito da heterose, visto que a composição racial dos animais Guzolando apresenta as raças Guzerá (Bos taurus-indicus) e Holandesa (Bos taurus-taurus). Considerando o efeito de complementariedade, pode-se destacar ainda o efeito da alta produção de leite na raça Holandesa e alta produção de sólidos na raça Guzerá. Em Minas Gerias, Ribeiro et al. (2017), também verificaram o bom desempenho de vacas cruzadas (F1) de Gir X Holandês na produção e leite a pasto. O cruzamento promove ganhos na produção e na composição do leite em sistemas de pastagens tropicais.

\section{Conclusão}

A suplementação em pastagens tropicais aumentou a produção de leite e sólidos no leite, sendo que a raça Guzolando apresentou maior desempenho, evidenciando o benefício da utilização de cruzamentos entre animais zebuínos e taurinos na produção de leite a pasto. 


\section{Referências}

Araújo, T. P. M., Rangel, A. H. N., Lima, G. F. C., Peixoto, M. G. C. D., Urbano, S. A., \& Bezerra, J. S. (2018). Gir and Guzerat cow milk production and composition according to lactation stage, somatic cell count, physiological state and body condition. Acta Scientiarum. Animal Sciences, 40(e39352), 1-7. https://doi.org/10.4025/actascianimsci.v40i1.39352.

Cardoso, R. B., Pedreira, M. S., Rech, C. L. S., Silva, H. G. O., Rech, J. L., Schio, A. R., Aguiar, L. V., Silva, A. S., \& Silva, H. A. (2017). Produção e composição química do leite de vacas em lactação mantidas a pasto submetidas à diferentes sistemas alimentares. Revista Brasileira de Saúde e Produção Animal, 18(1), 113-126. https://doi.org/10.1590/s1519-99402017000100011.

Carvalho, P. H. A., Borges, A. L. da C. C., Silva, R. R., Lage, H. F., Vivenza, P. A. D., Ruas, J. R. M., Facury Filho, E. J., Palhano, R. L. A., Gonçalves, L. C., \& Borges, I. (2018). Energy metabolism and partition of lactating Zebu and crossbred Zebu cows in different planes of nutrition. Plos One, 13(8), e0202088. https://doi.org/10.1371/journal.pone.0202088.

Carvalho, V. E., Araújo, S. A. C., Alves, D. O., Santos, C. C., \& Rocha, N. S. (2019). Dry matter intake and milk yield of cows grazing Xaraés palisadegrass under different management strategies. Acta Scientiarum. Animal Sciences, 41(1). https://doi.org/10.4025/actascianimsci.v41i1.46843.

Condren, S. A., Kelly, A. K., Lynch, M. B., Boland, T. M., Whelan, S. J., Grace, C., Rajauria, G., \& Pierce, K. M. (2019). The effect of by-product inclusion and concentrate feeding rate on milk production and composition, pasture dry matter intake, and nitrogen excretion of mid-late lactation spring-calving cows grazing a perennial ryegrass-based pasture. Journal of Dairy Science, 102(2), 1247-1256. https://doi.org/10.3168/jds.2018-14970.

Deresz, F. (2001). Produção de leite de vacas mestiças Holandês x Zebu em pastagem de capim-elefante, manejada em sistema rotativo com e sem suplementação durante a época das chuvas. Revista Brasileira de Zootecnia, 30(1), 197-204.

Ferreira, M. A., Valadares Filho, S. C., Inácio, M., Marcondes, M. L. P., Paulino, M. F., \& Valadares, R. F. D. (2009). Avaliação de indicadores em estudos com ruminantes: digestibilidade. Revista Brasileira de Zootecnia, 38(8), 1568-1573.

Figueiredo, C. B., Santana Júnior, H. A., Bezerra, L. R., Mendes, F. B. L., Santana, E. O. C., \& Abreu Filho, G. (2018). Correlations between production and economic variables in dairy cows on a tropical pasture. Acta Scientiarum. Animal Sciences, 40. https://doi.org/10.4025/actascianimsci.v40i1.39737. 2018.

Fukumoto, N. M., Damasceno, J. C., Deresz, F., Martins, C. E., Cóser, A. C., \& dos Santos, G. T. (2010). Milk yield and composition, feed intake and stocking rate of crossbread cows in tropical grasses managed in a rotational grazing system. Produção e Composição Do Leite, Consumo de Matéria Seca e Taxa de Lotação Em Pastagens de Gramíneas Tropicais Manejadas Sob Lotação Rotacionada, 39(7), 1548-1557. https://doi.org/10.1590/S1516-35982010000700022

Gomide, J. A. (1998). Fatores da produção de leite a pasto. Congresso Nacional de Estudantes de Zoootecnia, 1-32.

Hack, E. C., Bona Filho, A., Moraes, A. de, Carvalho, P. C. de F., Martinichen, D., \& Pereira, T. N. (2007). Características estruturais e produção de leite em pastos de capim-mombaça (Panicum maximum Jacq.) submetidos a diferentes alturas de pastejo. Ciência Rural, 37(1), 218-222.

Johansen, M., Søegaard, K., Lund, P., \& Weisbjerg, M. R. (2017). Digestibility and clover proportion determine milk production when silages of different grass and clover species are fed to dairy cows. Journal of Dairy Science, 100(11), 8861-8880. https://doi.org/10.3168/jds.2017-13401.

Lima, M. L. P., Berchielli, T. T., Nogueira, J. R., Ruggieri, A. C., Aroeira, L. J. M., Salman, A. K. D., \& Soares, J. P. G. (2001). Estimativa do consumo voluntário do capim-tanzânia (Panicum maximum, Jacq. cv. Tanzânia) por vacas em lactação sob pastejo rotacionado. Revista Brasileira de Zootecnia, 30(6), 1919-1924.

Manzano, R. P., Nussio, L. G., Campos, F. P., Andreucci, M. P., \& Costa, R. Z. M. (2007). Comportamento ingestivo de novilhos sob suplementação em pastagens de capim-tanzânia sob diferentes intensidades de desfolhação. Revista Brasileira de Zootecnia, 36(3), 550-557.

Mayilathal, K., Thirumathal, K., \& Thamihselvi, N. (2019). Seasonal variation in the composition of 
milk in different breeds of cow, at Dindigul District, Tamilnadu, India. International Journal of Animal Science, 3(1), 1043-.

NRC. (1989). Nutrient Requirements of Dairy Cattle (7th (ed.); 7th rev.). Natl. Acad. Press, Washington, DC.

Oliveira Filho, C. A. A., Machado, F. S., Ferreira, A. L., Tomich, T. R., Maurício, R. M., Campos, M. M., Silva, C. F. P. G., Azevêdo, J. A. G., \& Pereira, L. G. R. (2018). Nutritional plans on the intake, digestibility, and performance of dairy heifers of different breed compositions. Pesquisa Agropecuária Brasileira, 53(2), 247-255. https://doi.org/10.1590/s0100-204x2018000200014.

Ramírez-Rivera, E. J., Rodríguez-Miranda, J., Huerta-Mora, I. R., Cárdenas-Cágal, A., \& JuárezBarrientos, J. M. (2019). Tropical milk production systems and milk quality: a review. Tropical Animal Health and Production, 51(6), 1295-1305. https://doi.org/10.1007/s11250-019-01922-1.

Ribeiro, L. S., Goes, T. J. F., Torres Filho, R. A., Araújo, C. V, Reis, R. B., \& Saturnino, H. M. (2017). Desempenhos produtivo e reprodutivo de um rebanhoF1 Holandês x Gir em Minas Gerais. Arquivo Brasileiro de Medicina Veterinária e Zootecnia, 69(6), 1624-1634. https://doi.org/10.1590/1678-4162-9076.

Santos, S. A., Valadares Filho, S. C., Detmann, E., Ruas, J. R. M., Prados, L. F., \& Mariz, L. D. S. (2014). Intake, milk production and weight change curves for lactating Holstein $\mathrm{x}$ Zebu cows under grazing. Arquivo Brasileiro de Medicina Veterinária e Zootecnia, 66(3), 827-836. https://doi.org/10.1590/1678-41626201.

Sarkanen, K. V, \& Ludwig, C. H. (1971). Liguins. Occurrence, formation, structure, and reactions. Wildlife Disease Association.

Silva, D. J., \& Queiroz, A. C. (2002). Análise de alimentos: métodos químicos e biológicos (3rd ed.). Universdiade Federal de Viçosa.

Silva, H. A., Moraes, H. S. K. A., Hack, V. A. G. E., \& Faccio, P. C. F. (2008). Análise da viabilidade econômica da produção de leite a pasto e com suplementos na região dos Campos Gerais-Paraná. Ciência Rural, 38(2), 445-450.

Silva, J. A., Silva, C. G. M., Paula Sousa, D., Paula, N. F., Silva Carvalho, A. P., Macedo, B. G., Costa Júnior, W. S., Bianchi-Zanette, I. E., Costa, R. V., \& Teobaldo, R. W. (2017). Supplementation strategies for dairy cows kept in tropical grass pastures. Semina: Ciências Agrárias, 38(1), 401-416. https://doi.org/10.5433/1679-0359.2017v38n1p401.

Valadares Filho, S. C., Moraes, E. H. B. K., Detmann, E., Paulino, M. F., Valadares, R. F. D., Moraes, K. A. K., \& Marcondes, M. I. (2006). Perspectivas do uso de indicadores para estimar o consumo individual de bovinos alimentados em grupo. Reunião Anual Da Sociedade Brasileira de Zootecnia, 43(Sup.), 291-322.

Zanin, E., Henrique, D. S., \& Fluck, A. C. (2017). Avaliação de equações para estimar o consumo de vacas leiteiras. Revista Brasileira de Saúde e Produção Animal, 18(1), 76-88. https://doi.org/10.1590/S 1519-99402017000100008.

Histórico do artigo:

Recebido: 24 de março de 2021

Aprovado: 1 de maio de 2021
Licenciamento: Este artigoé publicado na modalidade Acesso Aberto sob a licença Creative Commons Atribuição 4.0 (CC-BY 4.0), a qual permite uso irrestrito, distribuição, reprodução em qualquer meio, desde que $\mathrm{o}$ autor e a fonte sejam devidamente creditados. 